\title{
Tradability of Services: The Role of Identity Maintenance
}

\author{
Peter Zweifel \\ Emeritus University of Zurich, Bad Bleiberg, Austria \\ Email: peter.zweifel@uzh.ch
}

How to cite this paper: Zweifel, P. (2021). Tradability of Services: The Role of Identity Maintenance. Journal of Service Science and Management, 14, 353-368. https://doi.org/10.4236/jssm.2021.143022

Received: May 22, 2021

Accepted: June 21, 2021

Published: June 24, 2021

Copyright (C 2021 by author(s) and Scientific Research Publishing Inc. This work is licensed under the Creative Commons Attribution International License (CC BY 4.0).

http://creativecommons.org/licenses/by/4.0/

(c) (i) Open Access

\begin{abstract}
This contribution is motivated by two observations that do not seem to have been seen in conjunction up to now. On the one hand, when the "French exception" was inserted in the General Agreement on Trade in Services (GATS) of the World Trade Organization (WTO), this was motivated by the fear that imports especially of cultural services would undermine a country's identity. On the other hand, while services presently account for up to $70 \%$ of the GDP of major industrial countries, their imports of services lag far behind with less than $20 \%$ of total imports. This raises the question of whether the desire to maintain a country's identity might exert a limiting influence on the trade in services. The analysis combines Lancaster's new theory of demand with (relative rather than absolute) identity maintenance (RIM) to derive a set of acceptable outcomes of service production in characteristics space. For trade in services to occur, the sets of trading countries need to overlap, resulting in three testable predictions: 1) The more stringent the countries' RIM, the smaller the volume of services trade between them; 2) In the presence of RIM, the volume of trade in services increases with the similarity of the countries' preference structures; and 3) in the presence of RIM, the volume of trade in services is the lower, the greater the difference in countries' incomes. While current evidence supports these predictions, it needs to be completed when more data on bilateral trade flows in services become available.
\end{abstract}

\section{Keywords}

Trade in Services, New Consumer Demand Theory, Identity Maintenance, General Agreement on Trade in Services (GATS)

\section{Introduction and Motivation}

An important literature claims that globalization and international trade un- 
dermine a country's cultural identity (Tomlinson, 1999; Coalition for the Diversity of Cultural Expression, 1998; Kaldor, 2004; Ariely, 2012; Ebtihal et al., 2017). At the same time, while services by now account for 77\% of GDP in the United States (65.5\% in the European Union, as of 2019), they amount to only $19 \%$ of U.S. imports (14.6\% of EU imports, respectively), indicating that trade in services has been developing but slowly compared to their domestic component. ${ }^{1}$ This contribution addresses the connection between these two phenomena. Given that there is a desire to maintain a society's identity, how does this impact on the direction and volume of international trade in services? The focus on services reflects the "French exception"2 (Collard, 2004), i.e. the French government's success in exempting cultural services from the General Agreement on Trade in Services (GATS) ${ }^{3}$. One of its main concerns was the preponderance of American movies. Evidently, the French exception had an effect: Only around 50\% of admissions in France are for American film imports, compared to $60 \%$ to $90 \%$ in other European film markets (GreenAsh, 2017), period of observation not indicated]. Of course, this is not to deny the importance of barriers to trade in services, notably a host of regulations (see Benz et al., 2020) for a recent listing and evidence that they are related to the volume of trade]. However, these regulations may at least to some degree reflect citizens' desire to maintain a country's identity.

Against this background, the plan of this paper is as follows. In Section 2 it introduces identity maintenance (which will be shown to be of a relative type, called RIM henceforth) into Lancaster's (1966) new consumer demand theory to show that it defines a set of 'acceptable' outcomes in characteristics space. In Section 3, this set is determined for two countries each of which is characterized by its own RIM to derive three predictions concerning trade in services: 1) The more stringent the countries' RIM, the smaller the volume of services trade between them; 2) In the presence of RIM, the volume of trade in services is the higher, the more similar the countries' preference structures; and 3) the volume of trade in services is the lower, the greater the difference in countries' incomes. These predictions are confronted with the (limited) empirical evidence on bilateral trade flows in services in Section 4; they receive a good deal of confirmation. Section 5 contains a summary and concluding remarks.

\section{Applying Lancaster's Theory to Services Subject to Identity Maintenance}

In Lancaster's (1966) new consumer demand theory, desirable characteristics of ${ }^{1}$ The data sources are https://data.worldbank.org/indicator/NV.SRV.TOTL.ZS, and https://tradingeconomics.com/european-union/imports.

${ }^{2}$ The French exception can be defined through 1) the powerful role of the central state, 2) a high degree of polarization in domestic conflicts, 3) a universalist mission, and 4) a unitary view of society. Elements 3) and 4) arguably are undermined by foreign cultural influence, in particular through international trade.

${ }^{3}$ Arguably films constitute material goods. However, their close relationship with services becomes evident when they are considered as an instance of the splintering off and disembodiment of services, a concept introduced by Bhagwati (1984). 
goods (often called attributes in marketing studies) are the main source of utility (rather than quantities of goods as in traditional Microeconomics). Let consumer's value two characteristics of a car, the so-called consumption technology is represented by points $A$ and $B$, respectively in Figure 1 . They indicate that model B dominates model A from a technological perspective because it features both higher fuel efficiency and more horsepower. However, this does not imply that $\mathrm{B}$ dominates $\mathrm{A}$ economically because it may have a higher user cost $k_{B}>k_{A}$ (consisting of the annuity on capital invested, maintenance, and operating cost). Let the consumer dispose of a budget $Y$, sufficient for driving model A during five years; accordingly, point A becomes point $5 \mathrm{~A}\left(=Y / k_{A}\right)$ in $\left(c_{1}, c_{2}\right)$-space. Evidently, the lower $k_{A}$, the greater the distance e.g. between points $2 \mathrm{~A}$ and $3 \mathrm{~A}$, indicating that a given income buys more of the two attributes. Conversely, point $2 \mathrm{~B}$ shows that the same budget is sufficient for merely two years of use. A doubling of the available budget from $Y$ to $2 Y$ lets the consumer attain the points $10 \mathrm{~A}$ and $4 \mathrm{~B}$ (assuming that the cars continue to deliver unchanged performance over time) on the same ray because the attribute mix remains the same.

The difference in user cost is such that the consumer (represented by indifference curves $\bar{u}$ and $\overline{\bar{u}}>\bar{u}$ ends up preferring model A given a budget equal to $Y$. Note that this may even hold for a consumer type who has a basic preference for model B (indicated by the dashed indifference curve in Figure 1).

Evidently, Lancaster's theory applies to the demand for differentiated goods. However, it is perfectly suitable for modelling the demand for services, which contrary to goods may be subject to a requirement of identity maintenance. Whereas the manufacturer of a car is free to choose the specification of its brand,

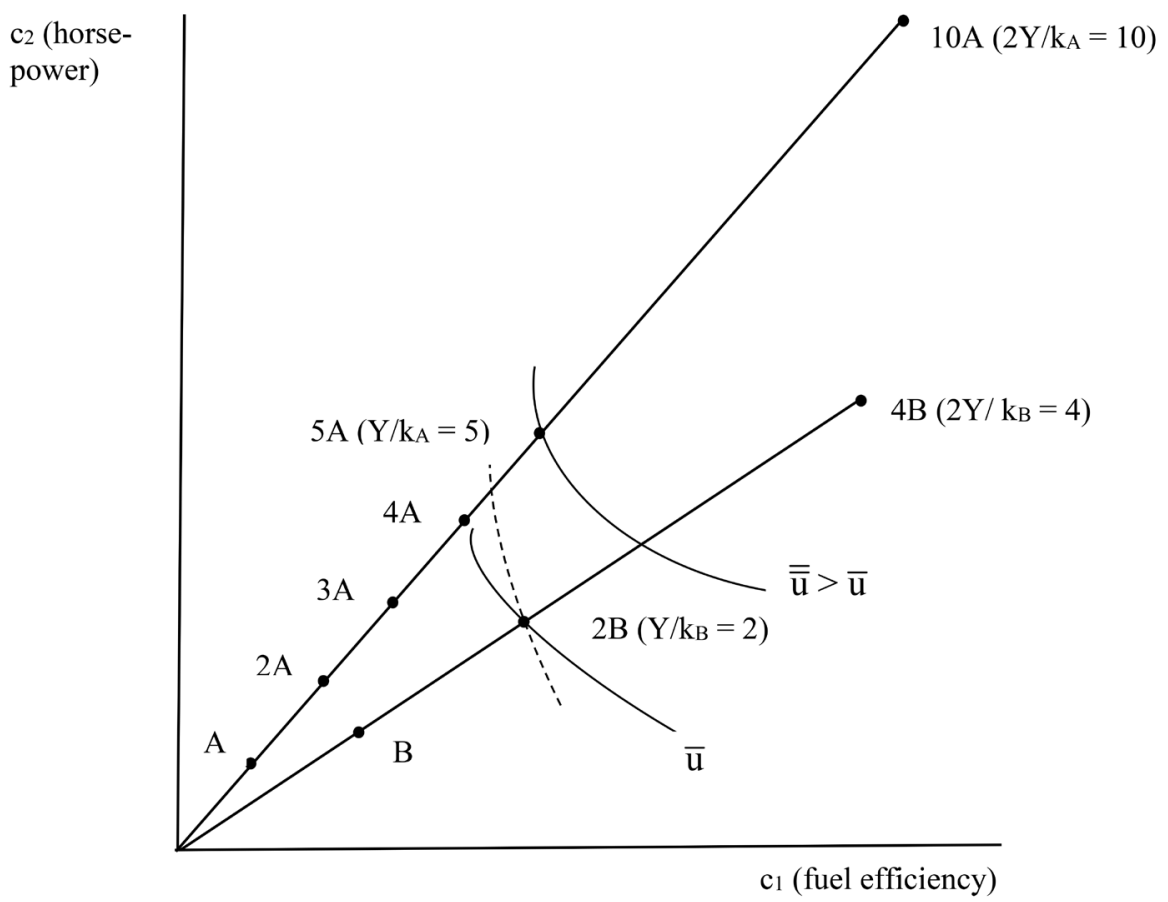

Figure 1. Characteristics, preferences, and user costs in case of a car. 
the provider of a repair service is expected to preserve the car's identity. As in Figure 1, the two characteristics valued by the consumer are fuel efficiency $\left(c_{1}\right)$ and horsepower $\left(c_{2}\right)$. Let point $\mathrm{E}^{\star}$ in Figure 2 represent the consumer's original optimum and $\mathrm{E}_{0}$, the actual situation after a drop in performance $\left(c_{2}\right)$ by the car's engine. There are two variants of identity maintenance that need to be distinguished:

1) Absolute identity maintenance. This would make $\mathrm{E}^{\star}$ the consumer's bliss point. Indifference curves would be circles centered at $E^{\star}$, implying that e.g. outcome $G$ of the service would be associated with a lower utility than $E^{\star}$ although it features more of both positively valued characteristics. This evidently violates the well-established microeconomic postulate of "more is better", making identity maintenance of the absolute type unrealistic.

2) Relative identity preservation $(R I P)$. In this case, the consumer values an unchanged mix of characteristics defining the product's identity, given by the ray along which $c_{1} / c_{2}$ remains constant. However, a change in this mix can be compensated by more of at least one characteristic; accordingly, the indifference curve $\bar{u}$ through a point such as $\mathrm{E}_{0}$ has the form of an ellipse. ${ }^{4}$ The hatched area indicates the set of outcomes that entail a utility level at least as high as $\bar{u}$, making them acceptable to the consumer ${ }^{5}$. This does not hold for an outcome like $\mathrm{H}$, although in the absence of RIM it could easily represent a gain in utility relative to a negatively sloped indifference curve even through $\mathrm{E}^{*}$ (dashed). This

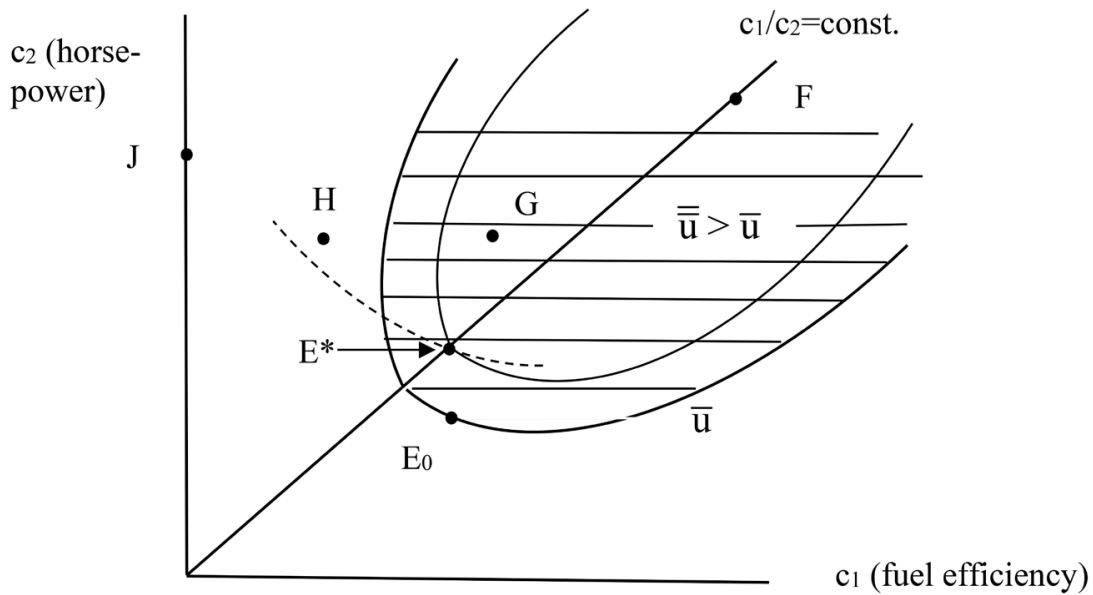

Figure 2. Relative identity maintenance (RIM) in the case of a repair service.

${ }^{4} \mathrm{An}$ ellipse is defined by the constancy of the sum of two distances from a reference line (called the major axis) measured from two focal points. Since the bliss point $\mathrm{E}^{\star}$ can be defined as the inner focal point, the line $c_{1} / c_{2}=$ const. in Figure 2 is the major axis; the outer focal point $\mathrm{F}$ lies on it as well. A point on the ellipse (the indifference curve) is characterized by two deviations from this line: 1) the utility gain due to higher values of $\left(c_{1}, c_{2}\right)$ compared to $E^{*}$, and 2$)$ the utility loss caused by the deviation from the $c_{1} / c_{2}=$ const. locus, measured from point $\mathrm{F}$. It is this constancy that defines the indifference curve [for further details, see e.g. Coxeter (1969: pp. 115-119)].

${ }^{5} \mathrm{An}$ attribute may be dichotomous. In this case, the set of acceptable outcomes under RIP can be determined as follows. Let $c_{1}$ be dichotomous, with value $c_{1}=1$ at $\mathrm{E}^{*}$ and 0 otherwise in Figure 2 . Then, a first part of the acceptable set consists of all points laying vertically above $\mathrm{E}^{\star}$. Its second part reflects the fact that there is an amount of $c_{2}$ such as indicated by point $J$ on the vertical axis which makes the consumer indifferent between it and $\mathrm{E}^{*}$; it consists of all points lying vertically above J. 
shows the cost of RIM in utility terms.

A RIM requirement characterizes many types of service. A few instances are given below.

Architecture and construction. Here, two relevant characteristics are outside appearance $\left(c_{1}\right)$ and functionality $\left(c_{2}\right)$. While for a new building RIM may not be relevant to the client (they may be for the city's building authority), they are of particular importance in the case of a renovation when clients want to recognize their property (Ahirwe, 2020).

Banking. The service of a bank could simply be defined in terms of the products it sells, whose main attributes are expected return $(\mu)$ and volatility $(\sigma)$. Acting as intermediaries, their remit would be to help customers reach their efficient frontier in $(\mu, \sigma)$-space. However, consumers' optima depend on their degree of risk aversion (see e.g. Pennacchi, 2007, ch. 2); therefore, they may well find it unacceptable if the bank were to restructure a conservative portfolio to become a highly risky one. The study by Seth et al. (2020) covering 18 countries indeed points to substantial inertia on the part of retail investors, arguably reflecting RIM.

However, a banking service could also be defined in terms of attributes valued by customers. Kuruppu, Dissanayake \& Madhakiva (2018) apply the SRVQUAL model (developed by Parasuraman, Zeithaml, \& Berry, 1988), to find that crucial attributes are reliability $\left(c_{1}\right)$ and $\left(c_{2}\right)$ assurance, while responsiveness, empathy and tangible goods (e.g. credit cards issued) do not seem to matter. Both $c_{1}$ and $c_{2}$ are related to the maintenance of identity, this time of the relationship between a client and his or her bank.

Insurance. As in banking, an insurer's service can be defined in terms of the product it sells. At the most basic level, it is coverage provided in case of loss, which has two components, the probability of payment in case of loss $\left(c_{1}\right)$ and the amount of compensation paid in case of loss $\left(c_{2}\right)$. Since the probability of payment has a maximum value of one, Figure 2 needs to be complemented by a line limiting the set of acceptable outcomes at $c_{1}=1$.

However, since insurance policies are mainly distributed through agents, their characteristics come close to determining quality. Among the eight qualities that make a good agent, Cussen (2021) cites the first two as meeting the client's needs $\left(c_{1}\right)$ and providing good customer service $\left(c_{2}\right)$. As to $c_{1}$, it is known that the demand for coverage not only depends on the value of the asset at risk but also the degree of risk aversion, a very individual parameter (Zweifel, Eisen, \& Eckles, 2021: ch. 3.3.2). The meaning of $c_{2}$ is that if a consumer has a question about the policy (which occurs often), the agent responds without much delay. Evidently, a deviation from the customary ratio $c_{1} / c_{2}$ constitutes a utility loss that would have to be compensated by other attributes, e.g. ample product knowledge. In sum, RIM seems at work in insurance as well.

Retail trade. One could argue that the characteristics of a retailer's service coincide with those of the products it sells. This has not proved true, however; 
for instance, in their questionnaire study of Indian consumers Ghosh, Tripathis \& Kumar (2010) identify no fewer than 11 store attributes. The Figure 1 is of particular interest because it shows that discounts cause a full $61 \%$ of respondents (the highest share) to switch stores. However, discounts arguably leave the other attributes of an outlet unchanged so correspond to a movement out on the $\left(c_{1} / c_{2}\right)$-ray of Figure 2. This evidence therefore again supports the notion of RIM at work.

Telecommunications. In the case of mobile telephony, a study performed by Telser et al. (2010: Table 8 and Figure 3) shows that dependability of connections $\left(c_{1}\right)$ and their quality (absence of signal noise or echo, $c_{2}$ ) matter greatly both to German and Swiss consumers. There is evidence of RIM in that for $29 \%$ of Swisscom customers, $c_{1}$ constitutes the most important and for $21 \%, c_{2}$ the second most important attribute, amounting to a ratio of 1.38 (=29/21). Among Swiss Sunrise customers, the figures are $18 \%$ and $15 \%$, respectively, i.e. a ratio of 1.20. For an equal share (29\%) of German customers of Deutsche Telekom, $c_{1}$ also ranks first and for $18 \%, c_{2}$, second. Among those signed up with Vodafone, the shares are $24 \%$ and $15 \%$, respectively; thus here the $c_{1} / c_{2}$-ratios are 1.61 $(=29 / 18)$ and $1.60(=24 / 15)$. The similarity of the two ratios in both countries supports the notion that customers who switch providers expect the ratio $c_{1} / c_{2}$ to remain roughly constant. However, calculated over the customers of the four Swiss and three German providers, the percentage ratios differ, with 1.20 $(=25 / 20)$ and $1.75(=28 / 16)$, respectively, pointing to a difference in preferences that will become important in Section 3.

Transport. Here, shortness of time in transit $\left(c_{1}\right)^{6}$ and level of service $\left(c_{2}\right)^{7}$ have been found to be significant attributes for Korean truckers in the stated choice study of Shin et al. (2019) ${ }^{8}$. The authors view truckers as consumers, i.e. as purchasers on behalf of their clientele. Their estimated marginal utility weights associated with $c_{1}$ and $c_{2}$ are 1.848 and 0.0143 , respectively for a trip of less than $20 \mathrm{~km}$ (see the authors' Table 6). Since according to Lancaster theory, quantities of characteristics are inversely related to marginal utilities, their quantity ratio is $\left(c_{1} / c_{2}\right)=0.0078(=0.0143 / 1.848)$. In the presence of RIM, this ratio should not change if the trip is longer than $20 \mathrm{~km}$ (the point $\mathrm{E}^{*}$ on the $\left(c_{1} / c_{2}\right)$-ray of Figure 2 simply shifts out). Indeed, the utility weights are 1.612 and 0.0152 in this case, resulting in a ratio of $0.0094^{9}$, whose similarity with 0.0078 supports the notion of RIM at work.

The study even provides the information necessary to derive the boundary of ${ }^{6}$ In Shin et al. (2019), time in transit is a negatively valued characteristic; for simplicity, it is redefined to become a positively valued one.

7"Level of service" comprises reliability (arrival on time), availability, absence of damage, information about location and arrival of cargo, connectivity with other modes of transport, and capacity to deal with a surge in demand.

${ }^{8}$ The authors also include the cost of loading, of a one-way transport of 14 tons, and of unloading as an attribute. In terms of Figure 1 and Figure 2, however, unit cost does not affect the angle of the (c1/c2)-ray but its length.

${ }^{9}$ In view of the coefficients' standard errors of at least 0.34 and 0.034 , the difference between 0.0078 and 0.0094 is statistically insignificant. 
acceptance at least locally. Assume that in the second setting, the ratio $\left(c_{1} / c_{2}\right)$ is marginally higher with 0.010 rather than 0.0094 , resulting in a loss of utility amounting to $0.636[=0.006(1.612 / 0.0152)]$. Since the coefficient of the cost attribute (measured in USD) is -0.558 , this associated loss of utility can be compensated by a cost reduction by 1.14 USD $(=0.636 / 0.558)$ or about 0.8 percent of average unit cost.

\section{Relative Identity Maintenance and Trade in Services: Three Predictions}

In this section, Figure 2 is generalized to two countries who differ in their preferences w.r.t. educational services (see Figure 3). Especially primary education is subject to RIM; for instance, in its national curriculum of basic education, the Department of Basic Education (2001) of Portugal stipulates that pupils between six and nine years old must be able to recognize and valorize expressions of the cultural and historic heritage of their region; at age ten to eleven, this requirement extends to historic heritage of the entire country. In the Greek curriculum for primary education, the objectives are defined as learning of aspects such as traditions and customs, contact with cultural heritage and is appreciation, and knowledge of the contribution of European to world culture (Apostolopoulou et al., 2014).

Ever since the taxonomy introduced by Bloom et al. (1956), the main objectives of education have been considered to be knowledge, affective skills, and action-based skills. In Figure 3, let there be two countries with educational systems which both seek to achieve knowledge $\left(c_{1}\right)$ and affective skills $\left(c_{2}\right)$. However, in country $\mathrm{F}$, the citizenry values affective skills relatively higher than in country $\mathrm{D}$. In the absence of RIM, point G indicates the outcome of a mutually beneficial trade in educational services since it is associated with an improvement in terms of both $c_{1}$ and $c_{1}$ in both countries ${ }^{10}$.

At this point, it is important to introduce an

Assumption. Producers of services in both countries are under the pressure of competition so need to satisfy domestic RIP before being able to export.

This assumption implies that in Figure 3, service production in both countries need to satisfy RIP, with acceptable outcomes delineated by indifference curves $\bar{u}^{\mathrm{D}}$ and $\bar{u}^{\mathrm{F}}$, respectively. It is in accordance with all four modes of services trade distinguished by the World Trade Organization (WTO, 2015). Mode 1 covers services supplied from one country to another such as remotely guided surgery; RIP clearly applies in both countries. Mode 2 relates to consumers or firms using a service abroad, as in the case of tourism or tertiary education, subject again to two-sided RIP at least to some extent. Mode 3 is associated with the establishment of a foreign subsidiary or branch; it often involves overlap of RIP because while headquarters export its business model, it needs to be accepted by customers in the host country. Finally, mode 4 is defined as individuals such as

${ }^{10}$ On the conditions governing the trade equilibrium, see Zweifel (1993: ch. A.0.3). 


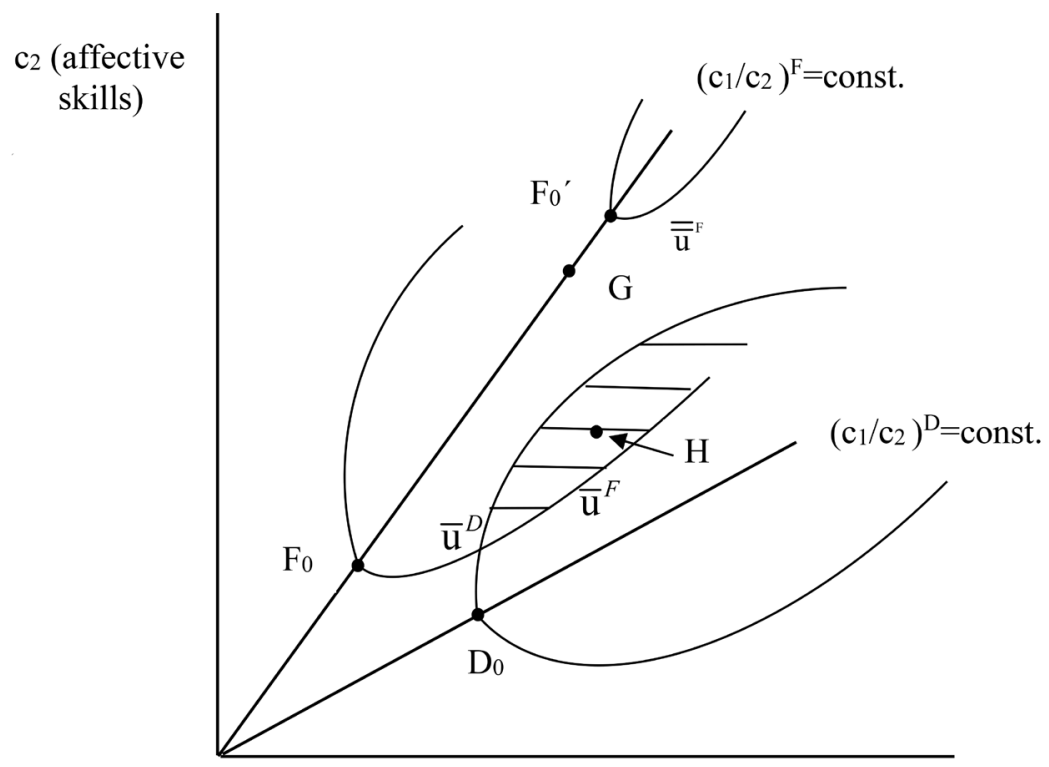

$\mathrm{c}_{1}$ (knowledge)

Figure 3. Relative identity maintenance and the tradability of educational services.

consultants traveling abroad. Again, they bring along their home business model, which however must meet with acceptance by their foreign clients-calling for overlap of RIP. Finally, the assumption is supported by research suggesting that exports and domestic sales are complements at least among locally-owned companies (Bardaji et al., 2017; Salomon \& Shaver, 2005) ${ }^{11}$.

Three predictions follow immediately from Figure 3.

Prediction 1. The more stringent relative identity maintenance (RIM) in trading countries, the smaller the volume of services trade between them.

In Figure 3, more stringent RIM means that the loss of utility due to a deviation from the country's $\left(c_{1} / c_{2}\right)=$ const. locus gains in importance relative to the utility gains due to a higher value of $c_{1}$ or $c_{2}$ (or both). For keeping utility constant, the indifference curve through $\mathrm{F}_{0}^{\prime}$ (say) must run closer to the $\left(c_{1} / c_{2}\right)^{\mathrm{D}}=$ const. locus than at $\mathrm{F}_{0}$. Ceteris paribus, this causes the (hatched) area of mutually beneficial trades to shrink (or become empty) and hence the volume of trade to fall.

Prediction 2. In the presence of relative identity maintenance (RIM), the volume of trade in services is the higher, the more similar the preference structures of the trading countries, contrary to conventional trade theory.

In terms of Figure 3, similarity of preferences means that the angle between the loci $\left(c_{1} / c_{2}\right)^{\mathrm{D}}=$ const. and $\left(c_{1} / c_{2}\right)^{\mathrm{F}}=$ const. is small. Ceteris paribus, this makes the area of mutual beneficial trades and hence the volume of service trade large. It may be noted that traditional (Heckscher-Ohlin) trade theory focuses almost exclusively on supply-side factors such as differences in factor endowments and factor intensities in production; however, especially for differentiated

${ }^{11}$ Neither study refers to services in particular; however there is no reason to assume that the evidence fails to apply to services. 
goods, differences in tastes become important (Markusen, 1986). Indeed, Movshuk (2005) found clear evidence for 24 categories of consumption in 115 countries suggesting that preferences differ substantially among poorer countries but much less so among rich ones. Even within the 19 OECD countries, this finding is confirmed by Shikher (2012), who uses his model estimated on 1989 data to simulate the effects of absence of differences in factor endowment, productivity, preferences, and of trade cost. He concludes that next to differences in productivity, differences in preferences are the second-most important determinant of trade volumes and specialization, also among poorer member countries. Due to RIM, the prediction is the opposite: Similarity of preferences induces trade in services.

Prediction 3. In the presence of relative identity maintenance (RIM), the volume of trade in services is the lower, the greater the difference in incomes of the two trading countries.

In Figure 3, let country $\mathrm{D}$ be richer than shown. Accordingly, the consumer's income $Y$ is higher, causing point $\mathrm{D}_{0}$ to shift out on the $\left(c_{1} / c_{2}\right)^{\mathrm{D}}=$ const. locus, and with it, the indifference curve $\bar{u}^{\mathrm{D}}$ ceteris paribus. As a consequence, the hatched area of mutual beneficial trades and hence the volume of service trade shrinks.

\section{Preliminary Evidence}

Since statistics on trade in services are patchy (Wettstein et al., 2018; Spinelli \& Miroudot, 2015), as late as 2011 a full $35 \%$ of the U.S. services trade volume could not be allocated geographically. However, for examining the impact of RIM, bilateral trade figures structured by country and industry are crucial. Yet some indirect (and partial) evidence is available in a number of instances.

Reverting to the trade in educational services analyzed in the preceding section, note that RIM not only governs primary but also tertiary education at least to some extent. The fear especially in less developed countries is that foreign providers of educational programs undermine the recipient country's educational ideas and practices (Altbach, 2001). Indeed, Larsen et al. (2002) estimate that even a country such as Greece that sends many students abroad, education imports account for only $1.9 \%$ of services imported. In terms of exports, Australia ranks first, with $11.8 \%$ of total exports of services; the United States and the United Kingdom are far behind with $3.5 \%$ and $3.2 \%$, respectively.

Another piece of indirect evidence comes from the fact that trade in educational services usually involves the migration of teachers and/or students. As to teachers, in the case of the United States only $11 \%$ of them are foreign-born, whereas the share of foreign-born individuals in the population amounts to $13 \%$ (Institute for Immigration Research, 2019). In Singapore, a country whose total exports and imports amount to $173.5 \%$ (145.6\%) of GDP as of $2019,{ }^{12}$ the share of foreign-born teachers is less than 1 percent of the total teaching population

${ }^{12}$ Source: https://data.worldbank.org/indicator/NE.EXP.GNFS.ZS?locations=SG. 
(Ong, 2019).

\subsection{Prediction 1}

This prediction states that the more marked the stringency of RIM of at least one of two trading countries, the smaller the volume of trade in services between them. Arguably, RIM is less restrictive if trading partners share the same language.

A piece of indirect evidence are the figures on trade in educational services collected by Larsen et al. (2002). Among the nine countries who provided data both on experts and imports, the market shares of both Australia and the United States are high, with $11.3 \%$ and $53.1 \%$ for exports and $7.8 \%$ and $56.1 \%$ for imports as of 2000. The United Kingdom is a big exporter with $20.5 \%$ but a small importer, with 3.3\% market share. It is to be expected that a sizable part of Australia's exports (imports) involves students from (to) the United States and the UK, while in the case of U.S. exports (imports), they importantly involve students from Australia and the UK. With regard to Australian imports, this expectation is confirmed in that in 2018-19 the United States ranked first and the United Kingdom $6^{\text {th }}$; however in terms of exports, China dominated, followed by India (Australian Government, 2020: pp. 116-117) ${ }^{13}$.

A counter-example is Mexico. Although a neighbor of the United States, it does not share the same language; moreover, its RIM is very stringent (Lopez, 2002). According to Larsen et al. (2002), the country's market share in educational exports was just $0.16 \%$ and in imports, $1.2 \%$ as of 2000 (the lowest among the nine countries sampled).

The impact of a common language on trade in services more generally has been estimated by Spinelli and Miroudot (2015). In a regression based on data from 74 countries and covering the years 1995 to 2011, this common feature is associated with about $30 \%$ more exports and imports of services (Table 2). The fact that the two countries share a common border seems also to increase export by about $30 \%$ but imports somewhat less. To balance these effects, distance (an indicator of cost associated with trade) would have to be at least 53\% lower for exports and even $70 \%$ lower for imports.

In sum, these findings support the notion that RIM has a limiting impact on trade in services.

\subsection{Prediction 2}

This prediction states that in the presence of RIM, trade in services is the higher, the more similar the preference structures of the trading countries. The World Trade Organization (2021) publishes country profiles w.r.t. trade in commercial services, indicating also major trading partners for a number of countries

For Belgium, it estimates that $7.5 \%$ of services exports go to Switzerland, making it the most important destination outside the European Union (EU). According to Parent (2008), in Belgium annual personal consumption expendi-

\footnotetext{
${ }^{13}$ The data comprise only education-related travel expenses.
} 
ture on education and transport was $0.90 \%$ and $15.5 \%$ of the total amounting to 12,668 USD (purchasing power parity-adjusted) as of 2005. The pertinent figures were $0.76 \%$ and $11.9 \%$ of 14,763 USD in Switzerland. Therefore, the two countries are rather similar in terms of income and structure of services consump$\operatorname{tion}^{14}$. While the profile for Switzerland does not report the main destinations of its services exports, the one for Belgium indicates that $3.3 \%$ of them originate in Switzerland, making it the main source country outside the EU.

Another instance of similarity are Australia and New Zealand, although Australians' total average consumption in 2005 was somewhat higher (14,036 USD) than New Zealanders' (11,524 USD). Yet their budget shares devoted to transportation are similar, with $15.8 \%$ and $17.1 \%$, respectively. ${ }^{15}$ This time, the trade figures are complete: $5.8 \%$ of Australia's exports of services go to New Zealand, where they account for $23.6 \%$ of its imports. Conversely, $20.4 \%$ of New Zealand's service exports go to Australia, where they account for $6.6 \%$ of its imports. While this constitutes support of the claim that similarity of preferences goes along with a greater volume of services trade, it is less than perfect because for both countries, China, the EU, and the United States are of comparable if not greater importance as trading partners.

\subsection{Prediction 3}

Prediction 3 states that in the presence of RIM, differences in income between trading countries lead to a reduction in the volume of services traded. According to the regression estimated by Spinelli and Miroudot (2015: Table 2), the GDP elasticity of services imports is 0.904 , that of exports 0.651 . This implies that the richer countries tend to be the importers of services. Now let the representative importing country become $50 \%$ richer, which ceteris paribus would go along with an increase of $45 \%=0.904 \times 50 \%$ ) of its imports. However, if the representative exporting country is $50 \%$ poorer, its exports (i.e. the rich country's imports $)$ are predicted to drop by $32.5 \%=(-0.651 \times 50 \%)$. Therefore, due to the increased difference in GDP, the volume of services trade increases only by an estimated $12.5 \%(=45 \%-32.5 \%)$. While this is not a reduction, it is suggestive of RIM putting a break on the growth of trade.

At a GDP per person of USD 40,247 as of 2019, Japan is one of the richest trading nations, while Serbia with USD 7412 is far poorer; but it does publish figures on services trade by origin and destination, contrary to most countries in the lower income group. It should be noted that with regard to merchandise trade, the two countries are amazingly similar, with manufactures accounting for 86.9\% (Japan) and $70.4 \%$ (Serbia) of their exports ${ }^{16}$. Yet for trade in services, both Serbia's exports to and imports from Japan are recorded in the "Other"

${ }^{14} \mathrm{An}$ earlier study by Clements, Wu \& Zhang $(2004,2006)$ also finds that with $11.48 \%$ and $11.32 \%$ respectively, the budget shares of transportation are very similar for Belgian and Swiss consumers.

${ }^{15}$ This similarity is again confirmed by the study of Clements, Wu \& Zhang $(2004,2006)$ with $14.59 \%$ and $15.80 \%$, respectively.

${ }^{16} \mathrm{~A}$ difference is that $64.8 \%$ of exports go to comparatively nearby EU countries in the case of Serbia but only $9.7 \%$ in the case of Japan. 
category (amounting to a total of $14.2 \%$ and $17.2 \%$, respectively), which is true of Japan as well (where the "Other category totals $35.4 \%$ and $0.8 \%$, respectively). Therefore, trade flows in services must be negligible, as predicted by RIM for two countries that differ so strongly in terms of their incomes. For a sharper test, one would have to know also the bilateral trade flows in merchandise, where RIM is hypothesized to be absent. All one can say that Japan is able to sell $19.1 \%$ of its merchandise exports to China but only $13.7 \%$ of its services exports (the import shares confirm the difference, with $9.4 \%$ but only $5.6 \%$, respectively as of 2018).

\section{Conclusion}

The starting point of this paper is a puzzle: Why is it that services make up more than $60 \%$ of the GDP of industrial countries while they account for less than $20 \%$ of their imports? The "French exception" from the General Agreement on Trade in Services (GATS) provides a first clue: The French government was concerned about a loss of cultural identity due to imports of entertainment services mainly from the United States. For incorporating the requirement of Relative Identity Maintenance (RIM) in a service, Lancaster's (1966) new demand theory is applied. Being defined in characteristics space rather than quantities space, it permits to define a set of acceptable outcomes of a service subject to RIM. For a trade in services to be beneficial for two countries, their sets of acceptable outcomes need to overlap. This insight generates three predictions: 1) In the presence of RIM, the volume of trade in services is the higher, the more similar the preference structures of the trading countries, 2) it is the higher, the more similar the countries' preference structures, and 3) it is the lower, the greater the difference in their incomes. Since there are few data on bilateral service trade flows, the evidence regarding these three predictions is mainly indirect. But it does tend to support them.

This study is subject to a number of limitations. For one, the volume of trade in services may be low due to protectionism. For instance, educational services by country $\mathrm{D}$ provided in country $\mathrm{F}$ can be taxed by the government of $\mathrm{F}$, creating a competitive edge in favor of domestic alternatives. A more subtle variant would be for $\mathrm{F}$ to require educational services to convey a degree of affective skills that providers from D cannot reach (in Figure 3, they would have to offer services with an amount of $c_{1}$ at least as high as indicated by point $G$, which is beyond D's set of acceptable outcomes). Of course, such hurdles can be overcome, notably by product differentiation resulting in a $\left(c_{1} / c_{2}\right)^{\mathrm{D}^{\prime}}$ closer to $\left(c_{1} / c_{2}\right)^{\mathrm{F}}$ just for export. The extra cost clearly has the same effect as a tax. Indeed, in their calculation of tax equivalents, Rouzet and Spinelli (2016) estimate surcharges due to trade restrictions in insurance (neglecting lack of regulatory transparency) of as low as $4 \%$ for Estonia but as high as $45 \%$ for India (as of 2012-2014). In the case of telecoms, Denmark has the lowest surcharge with $2 \%$, India is second-highest with $22 \%$. In view of the French exception, the case of 
motion pictures is of particular interest. However, the tax equivalent of trade restrictions is $12 \%$ in the case of France, far lower than e.g. China's of $23 \%{ }^{17}$ Therefore, protectionism may well be motivated by the desire to preserve a country's cultural identity, i.e. RIM.

Second, causality might run the other way round, with RIM induced by a volume of imported services that are perceived as threatening. As mentioned above, the French exception was a response to the liberalization initiatives of GATS. However, an analysis of this reverse causation would call for a public choice approach leading far beyond the confines of the present contribution.

Finally, one could complete the demand side with a production side to derive an equilibrium in the guise of Janeba (2004). Since buying a foreign good is associated with a loss of utility for the consumer, the conditions on which trade liberalization has a positive effect on social welfare can be studied. The downside of this more elaborate approach is that it does not yield testable predictions.

In spite of these limitations, this novel analysis of the impact of relative identity maintenance (RIM) on trade in services generates three predictions which become increasingly testable when more data on bilateral trade flows become available. In the presence of RIM, the volume of trade in services depends negatively on their stringency, positively on the similarity of preferences between countries, and negatively on the difference in countries' incomes. In conclusion, future research might concentrate not only on the impact of an increasing volume of trade in services on countries' identity but also on the desire to maintain it as a negative influence on services trade and the concomitant cost in terms of forgone benefits created by trade.

\section{Acknowledgments}

This paper has benefited from suggestions by an anonymous referee which resulted in an improvement of exposition. The usual disclaimer applies.

\section{Conflicts of Interest}

The author declares no conflicts of interest regarding the publication of this paper.

\section{References}

Ahirwe, B. (2020). Extending the Role of Architecture in Preserving and Representing Cultures across Communities. Tufts Intellectual Commons, 12 October. https://sites.tufts.edu/intellectualcommons/2020/10/23/extending-the-role-of-architect ure-in-preserving-and-representing-cultures-across-communities/

Altbach, P. (2001). Why Higher Education Is Not a Global Commodity. Chronicle of Higher Education, 11 May.

Apostolopoulou, A. P., Carvoreias, L. M., \& Klonari, A. (2014). Cultural Heritage and

https://web.archive.org/web/20141026015328/http://www.cdc-ccd.org/IMG/pdf/Culture-trade_histo ry_Eng.pdf 
Education. Integrating Tour Maps in a Bilateral Project. European Journal of Geography, 5, 67-77.

Ariely, G. (2012). Globalisation and the Decline of National Identity? An Exploration across Sixty-Three Countries. National and Nationalism, 18, 461-482. https://doi.org/10.1111/j.1469-8129.2011.00532.x

Australian Government (2020). Trade in Services, Australia 2018-19. Canberra: Department of Foreign Affairs and Trade. https://www.dfat.gov.au/sites/default/files/trade-in-services-australia-2018-19.pdf

Bardaji, J., Bricongne, C., Campagne, B., \& Gaulier, G. (2017). Domestic and Export Performances of French Firms. World Economy, 42, 785-817. https://doi.org/10.1111/twec.12713

Benz, S., Ferencz, J., \& Nordås, H. K. (2020). Regulatory Barriers to Trade in Services: A New Database and Composite Indices. The World Economy, 43, 2860-2979. https://doi.org/10.1111/twec.13032

Bhagwati, J. N. (1984). Splintering and Disembodiment of Services and Developing Nations. The World Economy, 7, 133-144. https://doi.org/10.1111/j.1467-9701.1984.tb00265.x

Bloom, B. S., Engelhart, M. D., Furst, E. J., Hill, W. H., \& Krathwohl, D. R. (1956). Taxonomy of Educational Objectives: The Classification of Educational Goals. New York, NY: McKay Company.

Clements, K. W., Wu, Y., \& Zhang, J. (2004). Comparing International Consumption Patterns. Discussion Paper No. 04.04, Perth: University of Western Australia.

Clements, K. W., Wu, Y., \& Zhang, J. (2006). Comparing International Consumption Patterns. Empirical Economics, 31, 1-30. https://doi.org/10.1007/s00181-005-0012-y

Coalition for the Diversity of Cultural Expression (1998). History and Mission. https://cdec-cdce.org/en/about/

Collard, S. (2004). The Elusive French Exception. In E. Godin, \& T. Chafer (Eds.), The French Exception (pp. 30-44). New York, NY: Berghahn Books.

Cussen, M. P. (2021). Eight Qualities that Make a Good Insurance Agent. https://www.investopedia.com/financial-edge/1212/8-qualities-that-make-a-good-insur ance-agent.aspx

Department of Basic Education (2001). National Curriculum of Basic Education. Lisbon, Portugal: Ministry of Education.

Ebtihal, M. A., Ghada Gamal, E., \& Haga Gaber, M. et al. (2017). The Impact of Globalization on Identity and Values of Citizenship. Berlin: Democratic Arabic Center for Strategic, Political and Economic Studies.

Ghosh, P., Vibhuti, T., \& Kumar, A. (2010). Customer Expectations of Store Attributes: A Study of Organized Retail Outlets in India. Journal of Retail and Leisure Property, 9, 75-87. https://doi.org/10.1057/rlp.2009.27

GreenAsh (2017). World Domination by Box Office Cinema Admissions. https://greenash.net.au/thoughts/2011/07/world-domination-by-box-office-cinema-ad $\underline{\text { missions/ }}$

Institute for Immigration Research (2019). A Portrait of Foreign-Born Teachers in the United States. Fairfax, VA: Institute for Immigration Research. https://iir.gmu.edu/publications/industries/education

Janeba, E. (2004). International Trade and Cultural Identity. NBER Working Paper No. 10426. New York, NY: National Bureau of Economic Research. https://doi.org/10.3386/w10426 
Kaldor, M. (2004). Nationalism and Globalisation. Nations and Nationalism, 10, 161-177. https://doi.org/10.1111/j.1354-5078.2004.00161.x

Kuruppu, C., Diassanayake, L. D. A. D., \& Madhakiva, W. D. N. (2018). Ralationship between Service Quality and Customer Satisfaction in Banking Services. 8th Annual International Conference on Business and Economics, Singapore, 26-27 November 2018.

Lancaster, K.J. (1966). A New Approach to Consumer Theory. Journal of Political Economy, 74, 132-157. https://doi.org/10.1086/259131

Larsen, K., Martin, J. P., \& Morris, R. (2002). Trade in Educational Services: Trends and Emerging Issues. The World Economy, 25, 849-868. https://doi.org/10.1111/1467-9701.00466.

Lopez, F. H. (2002). The Construction of Mexican Identity. Rutgers Law Review, 54, 989-996.

Markusen, J. R. (1986). Explaining the Volume of Trade: An Eclectic Approach. American Economic Review, 76, 1002-1011.

Movshuk, O. (2005). International Differences in Consumer Preferences and Trade: Evidence from Multicountry, Multiproduct Data. Working Paper, Gofuku (Japan): Toyama University.

https://www.jsie.jp/kansai2/Kansai_AM/0506_Okinawa/english/movshuk_fp.pdf

Ong, J. (2019). Number of Teachers in Singapore from Abroad Has Nearly Halved Since 2011. The Straits Times, 15 Mar.

Parasuraman, P. A., Zeithaml, V. A., \& Berry, L. L. (1988). SERVQUAL: A Multiple-Item Scale for Measuring Consumer Perception of Service Quality. Journal of Retailing, 64, $12-40$.

Parent, B. (2008). Personal Conumption Expenditure-International Comparison. http://www.worldsalaries.org/personal-consumption-expenditure.shtml

Pennacchi, G. (2007). Theory of Asset Pricing. Hoboken, NJ: Prentice Hall.

Salomon, R., \& Shaver, J. M. (2005). Export and Domestic Sales: Their Relationships and Determinants. Strategic Management Journal, 26, 855-871.

https://doi.org/10.1002/smj.481

Seth, H., Talwai, H., Bhatia, A., Saxena, A., \& Dhir, A. (2020). Consumer Resistance and Inertia of Retail Investors: Development of the Resistance Adoption Inertia Continuance (RAIC) Framework. Journal of Retailing and Consumer Services, 55, Article ID: 102071. https://doi.org/10.1016/j.jretconser.2020.102071

Shikher, S. (2012). Determinants of Trade and Specialization in the Organization for Economic Co-operation and Development Countries. Economic Inquiry, 51, 138-158. https://doi.org/10.1111/j.1465-7295.2012.00465.x

Shin, S., Roh, H.-S., \& Hur, S. H. (2019). Characteristics Analysis of Freight Mode Choice Model According to the Introduction of a New Freight Transport System. Sustainability, 11, Article No. 1209. https://doi.org/10.3390/su11041209

Spinelli, F., \& Miroudot, S. (2015). Estimating Bilateral Trade in Services by Industry-The EBTSDI Data Set. Paris: Organisation für wirtschaftliche Zusammenarbeit und Entwicklung.

Telser, H. Leukert, K., Berner, S. et al. (2010). Internationaler Vergleich von Präferenzen für Telekomangebote (International Comparison of Preferences for Telecom Services). Report Prepared for Swisscom, Olten: Polynomics.

Tomlinson, J. (1999). Globalization and Culture. Chicago, IL: University of Chicago Press.

Wettstein, S., Liberatore, A., Magdeleine, J., \& Maurer, A. (2018). A Global Trade in Ser- 
vices Data Set by Sector and by Mode of Supply (TISMOS). Geneva: World Trade Organization.

https://www.wto.org/english/res_e/statis_e/daily_update_e/Tismos_methodology.pdf

World Trade Organization (2015). Trade in Services: The Most Dynamic Segment of International Trade. Geneva: World Trade Organization. https://doi.org/10.30875/9d728647-en

World Trade Organization (2021). Trade Profiles 2020. Geneva: World Trade Organization. https://www.wto.org/english/res_e/publications_e/trade_profiles20_e.htm

Zweifel, P. (1993). Services in Switzerland: Structure, Performance, and Implications for European Economic Integration. Berlin: Springer. https://doi.org/10.1007/978-3-642-78552-8

Zweifel, P., Eisen, R., \& Eckles, D. L. (2021). Insurance Economics (2nd ed.). New York, NY: Springer. (In Print)

Coxeter, H.S.M. (1969). Introduction to Geometry, 2nd Edition. New York: Wiley.

Rouzet, D., \& Spinelli, F. (2016). Services Trade Restrictions, Mark-Ups, and Competition. OECD Trade Policy Paper 195, Paris: OECD. 